\title{
Produção de forragem, características estruturais e eficiência de utilização do nitrogênio em forrageiras tropicais sob adubação nitrogenada
}

\section{Forage yield, structural characteristics and nitrogen use efficiency in tropical forages under nitrogen fertilizer}

\author{
Deise Dalazen Castagnara ${ }^{1 *}$; Tiago Zoz ${ }^{2}$; Alexandre Krutzmann ${ }^{3}$; Aline Uhlein \\ Eduardo Eustáquio Mesquita ${ }^{5}$; Marcela Abbado Neres ${ }^{6}$; Paulo Sergio Rabello de \\ Oliveira ${ }^{7}$
}

\section{Resumo}

O presente trabalho objetivou avaliar os efeitos de doses crescentes de nitrogênio sobre as características morfogênicas, estruturais e produtivas das gramíneas Panicum maximum cvs. Mombaça e Tanzânia, e Brachiaria sp. Mulato. O experimento foi conduzido em condições de campo. O delineamento experimental utilizado foi de blocos casualizados em esquema fatorial $3 \times 4$, com três forrageiras (Panicum maximum cvs. Tanzânia e Mombaça e Brachiaria sp. cv. Mulato), quatro doses de N (0, 40, 80 e $160 \mathrm{~kg}$ $h^{-1}$ ), com três repetições. Foram avaliados os seguintes parâmetros: produção de massa verde (PMV), produção de massa seca (PMS), altura de planta, porcentagem de massa seca, folhas por perfilho, taxa de acúmulo de massa seca (TAMS) e eficiência de uso de nitrogênio (EUN). Os capins Mombaça e Tanzânia apresentaram resultados semelhantes, e ambos foram superiores ao capim Mulato quanto à produção de matéria verde e seca. As três espécies forrageiras responderam a aplicação de nitrogênio, com aumento na produção de MS, MV, TAMS, altura e número de perfilhos. A eficiência máxima no uso do $\mathrm{N}$ foi obtida com a dose de $120 \mathrm{~kg} \mathrm{ha}^{-1}$.

Palavras-chave: Brachiaria, Panicum, taxa de acúmulo

\begin{abstract}
This study aimed to evaluate the effects of increasing doses of nitrogen on the morphogenesis, structural and productive grass Panicum maximum cvs. Mombaca and Tanzania, and Brachiaria sp. Mulato. The experiment was conducted under field conditions. The experimental design was randomized blocks in a $3 \mathrm{x} 4$ factorial design with three forages (Panicum maximum cvs. Tanzania and Mombaca and Brachiaria sp. cv. Mulato), four $\mathrm{N}$ rates $\left(0,40,80\right.$ and $\left.160 \mathrm{~kg} \mathrm{ha}^{-1}\right)$ with three replications. Were evaluated the following parameters: fresh matter production (FMP), dry matter production (DMP), plant height, percentage of dry matter, leaves per tiller, dry matter accumulation rate (DMAR) and nitrogen use efficiency (NUE). Grasses Mombasa and Tanzania showed similar results, and both were superior
\end{abstract}

\footnotetext{
${ }^{1}$ Doutoranda em Agronomia, Universidade Estadual do Oeste do Paraná, UNIOESTE, Marechal Cândido Rondon, PR. E-mail: deisecastagnara@yahoo.com.br

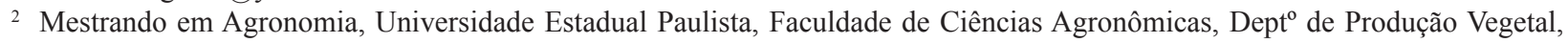
Botucatu, SP. E-mail: tiago_zoz@hotmail.com

3 Mestrando em Zootecnia, Universidade Estadual de Maringá, UEM. Maringá, PR. E-mail: alexandrekrutzmamm@yahoo.com

4 Graduando em Agronomia, UNIOESTE, Marechal Cândido Rondon, PR. E-mail: alineuhl@hotmail.com

5 Prof. Dr. da UNIOESTE, Marechal Cândido Rondon, PR. E-mail: e-mesquita@bol.com.br

6 Prof $^{\mathrm{a}} \mathrm{Dr}^{\mathrm{a}}$ da UNIOESTE, Marechal Cândido Rondon, PR. E-mail: mabbadoneres@yahoo.com.br

7 Prof. Dr. da UNIOESTE, Marechal Cândido Rondon, PR. E-mail: rabello.oliveira@hotmail.com

* Autor para correspondência
} 
to Mulato grass for the production of fresh and dry matter. The three species responded to nitrogen application, with an increase in FMP, DMP, DMAR, height and number of tillers. The maximum efficiency in use of $\mathrm{N}$ was obtained with a dose of $120 \mathrm{~kg} \mathrm{ha}^{-1}$.

Key words: Brachiaria, Panicum, accumulation rate

\section{Introdução}

O Brasil possui o maior rebanho comercial bovino do mundo e as pastagens cobrem 185 milhões de hectares, ou seja, cerca de $20 \%$ de sua área agricultável (MOREIRA et al., 2006), representando a base dos sistemas de produção de bovinos (SANTANA et al., 2010). A atividade apresenta grande potencial produtivo pela disponibilidade de área e características das espécies forrageiras, porém, os resultados econômicos obtidos pela maioria dos pecuaristas brasileiros são bastante inferiores aos patamares de produção possíveis de serem obtidos (VITOR et al., 2009).

A forma extrativista de exploração pecuária vem aumentando as áreas degradadas de pastagem ou em processo de degradação. Na degradação das pastagens, a produtividade e a composição botânica podem ser substancialmente alteradas ao longo do tempo, devido ao declínio da fertilidade do solo e ao manejo inadequado das plantas forrageiras. $\mathrm{O}$ esgotamento da fertilidade do solo, em consequência da ausência de adubação, tem sido apontado como uma das principais causas da degradação de pastagens cultivadas (COSTA et al., 2010).

Um dos motivos relacionados ao déficit produtivo da pecuária e ao declínio na produtividade das pastagens após 4 a 10 anos de pastejo é a baixa fertilidade dos solos brasileiros, com destaque para a baixa disponibilidade de fósforo e nitrogênio (SANTOS et al., 2002).

O nitrogênio é um dos nutrientes mais importantes na produção das gramíneas forrageiras (FRANÇA et al., 2007) por compor compostos orgânicos essenciais, como aminoácidos e proteínas, ácidos nucléicos, hormônios e clorofila (LAVRES JUNIOR; MONTEIRO, 2003).
Apesar do potencial produtivo das plantas forrageiras ser determinado geneticamente (FAGUNDES et al., 2005), a produtividade pode ser estimulada por meio da adubação nitrogenada, podendo variar quanto à dose e espécies utilizadas (GARCEZ NETO et al., 2002). Além do potencial produtivo, as características morfogênicas e morfofisiológicas do dossel também podem responder a adubação nitrogenada (PREMAZZI et al., 2003).

Garcez Neto et al. (2002) obtiveram expressivas respostas das características morfogênicas e estruturais do capim mombaça com a utilização de adubação nitrogenada, caracterizando o importante papel do $\mathrm{N}$ como ferramenta para manipular a estrutura da planta, possibilitando melhor alocação dos recursos produtivos no processo de crescimento e desenvolvimento.

Este trabalho foi proposto com o objetivo de avaliar os efeitos de doses crescentes de nitrogênio sobre as características morfogênicas, estruturais e produtivas das gramíneas Panicum maximum cvs. Mombaça e Tanzânia, e Brachiaria sp. cv. Mulato.

\section{Material e Métodos}

$\mathrm{O}$ experimento foi conduzido em condições de campo, na fazenda experimental "Professor Antônio Carlos dos Santos Pessoa", pertencente à Universidade Estadual do Oeste Paraná - Campus Marechal Cândido Rondon, localizado na região Oeste do Paraná, sob latitude $24^{\circ} 33^{\prime} 22^{\prime \prime} \mathrm{S}$ e longitude $54^{\circ} 03^{\prime} 24^{\prime}$ ' W, com altitude aproximada de $400 \mathrm{~m}$.

O clima da região segundo a classificação de Köppen (CRITCHFIELD, 1960), é do tipo Cfa (clima subtropical úmido com temperaturas médias 
anuais variando entre $17{ }^{\circ} \mathrm{C}$ e $19^{\circ} \mathrm{C}$ e precipitação média anual de $1500 \mathrm{~mm}$ ). Os dados climáticos referentes ao período experimental foram obtidos a partir de estação climatológica automática distante cerca de $400 \mathrm{~m}$ da área experimental, e estão representados na Figura 1.
O delineamento experimental utilizado foi de blocos casualizados em esquema fatorial $3 \times 4$, com três forrageiras (Panicum maximum cvs. Tanzânia e Mombaça e Brachiaria sp. cv. Mulato), quatro doses de $\mathrm{N}\left(0,40,80\right.$ e $\left.160 \mathrm{~kg} \mathrm{ha}^{-1}\right)$, com três repetições.

Figura 1. Temperaturas máxima, média e mínima, precipitação pluviométrica acumulada semanalmente e radiação solar e durante o período de condução do experimento.

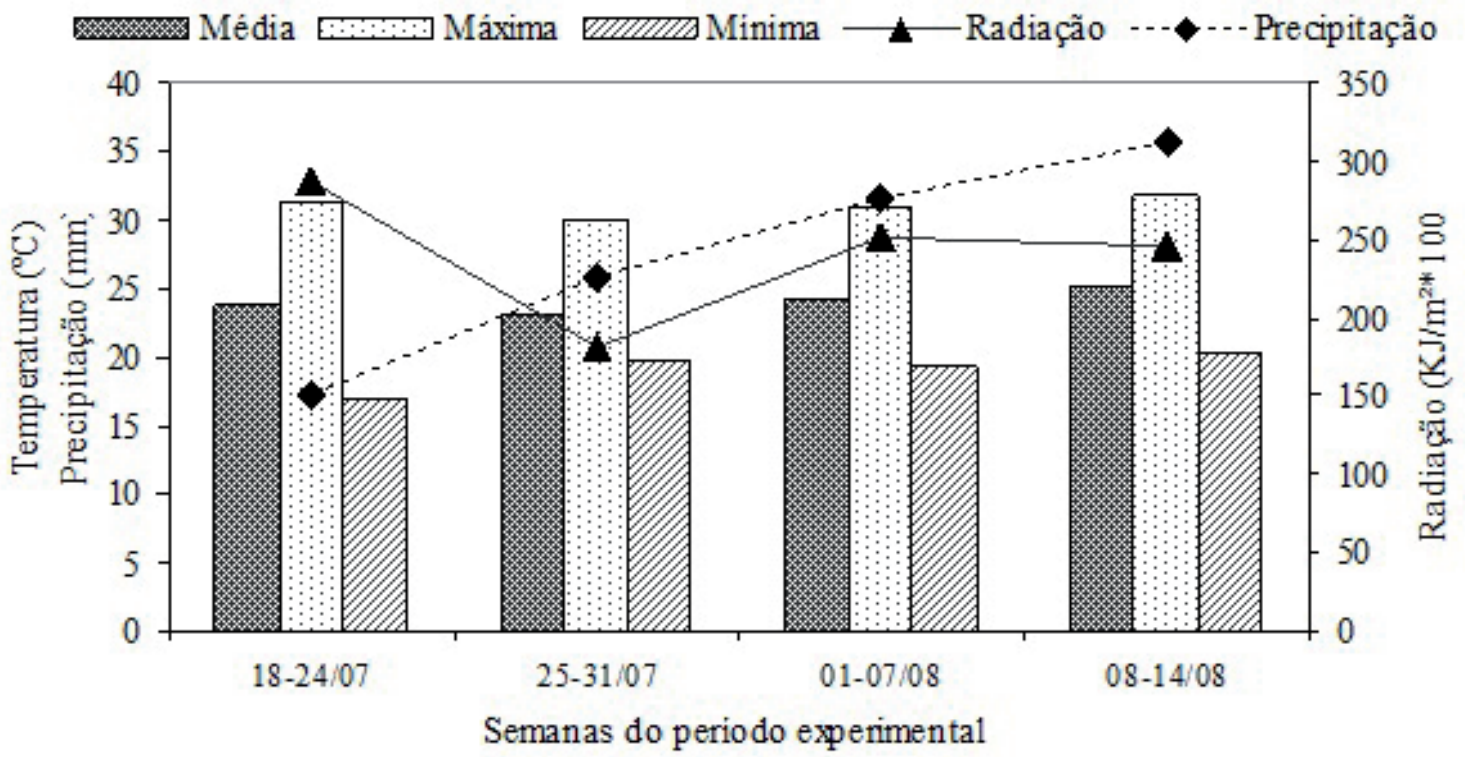

O experimento foi implantado em $2005 \mathrm{em}$ um Latossolo Vermelho (EMBRAPA, 2006). A amostragem do solo foi realizada previamente à implantação das gramíneas, e a análise química apresentou as seguintes características na camada 0-20 cm: $\mathrm{pH}$ em $\mathrm{H}_{2} \mathrm{O}$ : 5,0; Fósforo disponível (Mehlich-1): 4,18 $\mathrm{g} \mathrm{dm}^{-3}$; K (Mehlich-1): 0,19 $\mathrm{cmol}_{\mathrm{c}} \mathrm{dm}^{-3} ; \mathrm{Ca}^{+2}\left(\mathrm{KCl} 1 \mathrm{~mol} \mathrm{~L}^{-1}\right): 3,99 \mathrm{cmol}_{\mathrm{c}} \mathrm{dm}^{-}$ 3; $\mathrm{Mg}^{+2}\left(\mathrm{KCl} 1 \mathrm{~mol} \mathrm{~L}^{-1}\right): 2,39 \mathrm{cmol}_{\mathrm{c}} \mathrm{dm}^{-3}{\text { e } \mathrm{Al}^{+3}}^{+3}$ ( $\left.\mathrm{KCl} 1 \mathrm{~mol} \mathrm{~L}^{-1}\right): 0,05 \mathrm{cmol}_{\mathrm{c}} \mathrm{dm}^{-3} ; \mathrm{H}+\mathrm{Al}$ (acetato de cálcio 0,5 $\mathrm{mol} \mathrm{L}^{-1}$ ): 7,20 $\mathrm{cmol}_{\mathrm{c}} \mathrm{dm}^{-3}$; SB: 6,57 $\mathrm{cmol}_{\mathrm{c}} \mathrm{dm}^{-3}$; Saturação por bases 47,71\%, Matéria orgânica (Método Boyocus): 31,44 $\mathrm{g} \mathrm{dm}^{-3}$. Com base na análise de solo o $\mathrm{pH}$ foi corrigido com calcário dolomítico $\left(3,4\right.$ toneladas $\left.\mathrm{ha}^{-1}\right)$ para elevação da saturação por bases a 70\%. Por ocasião da semeadura, além da correção do pH do solo, foi realizada adubação potássica com $60 \mathrm{~kg} \mathrm{ha}^{-1}$ de $\mathrm{K}_{2} \mathrm{O}$, utilizando-se como fonte o cloreto de potássio; adubação fosfatada com $100 \mathrm{~kg} \mathrm{ha}^{-1}$ de $\mathrm{P}_{2} \mathrm{O}_{5}$, utilizando-se como fonte $\mathrm{o}$ superfosfato triplo.

Em setembro de 2005 foi efetuada a semeadura das gramíneas nas parcelas com dimensões de 3x4 m em linhas espaçadas de 0,4 m.

A área permaneceu sob manejo constante, com roçadas e limpezas periódicas para assegurar o estabelecimento da pastagem. Em 18 de dezembro de 2007 foi realizada a roçada de uniformização da pastagem, com a aplicação da adubação nitrogenada segundo os tratamentos tendo como fonte de $\mathrm{N}$ a uréia.

As avaliações foram realizadas com a idade de 
rebrota de 35 dias. Para a determinação da altura do dossel forrageiro, foram tomadas as alturas em 10 pontos aleatórios dentro de cada parcela por meio de régua graduada em centímetros, com posterior cálculo da média. Para determinação da produção de matéria seca (PMS) e do número de folhas por perfilho as amostras foram coletadas com auxílio de um quadrado de ferro com área conhecida $\left(0,25 \mathrm{~m}^{2}\right)$ e uma tesoura de poda, de forma que o quadrado foi jogado três vezes de forma aleatória dentro da área útil de cada parcela e todas as plantas existentes no seu interior foram cortadas a uma altura de $15 \mathrm{~cm}$ e embaladas em sacos plásticos para condução ao laboratório.

No laboratório do núcleo de estações experimentais, os sacos plásticos com as amostras foram pesados para determinação da produção de matéria verde (PMV) por hectare. Para a determinação dos teores de matéria seca (\%MS) foi retirada uma sub-amostra de aproximadamente $400 \mathrm{~g}$, que foi embalada em saco de papel e conduzida à estufa com ventilação forçada de ar a temperatura de $55^{\circ} \mathrm{C}$ por 96 horas para secagem (SILVA; QUEIROZ, 2006) e posterior determinação da produção de MS por hectare. Para a determinação do número de folhas por perfilho, foram selecionados 10 perfilhos ao acaso de cada amostra, para posterior cálculo da média por parcela.

A taxa de acúmulo diário de matéria seca foi obtida através da razão entre a produção total de matéria seca e o número de dias do período experimental. Já a determinação da eficiência da utilização do $\mathrm{N}$ pela forragem foi obtida subtraindo-se da produção total de MS (kg de MS ha-1) de cada tratamento com nitrogênio a produção do tratamento sem adubação nitrogenada. A diferença de produção foi dividida pela dose total de $\mathrm{N}$ empregada no respectivo período e tratamento. A relação $\mathrm{kg}$ de MS kg de $\mathrm{N}^{-1}$ representou quantos $\mathrm{kg}$ de $\mathrm{MS}$ foram produzidos para cada $1 \mathrm{~kg}$ de $\mathrm{N}$ aplicado na pastagem, demonstrando a eficiência de utilização do nutriente.

Os dados obtidos foram submetidos à análise estatística por meio do programa Sisvar 5.3 (FERREIRA, 2008). Quando constatada significância pela análise de variância as doses de $\mathrm{N}$ foram comparadas por meio de análise de regressão e, para escolha do modelo, considerouse significância de 5\% para os coeficientes das equações e o coeficiente de determinação, enquanto as forrageiras foram comparadas pelo teste Tukey ao nível de $5 \%$ de probabilidade.

\section{Resultados e Discussão}

Não foi verificada interação significativa entre as espécies forrageiras e as doses de nitrogênio aplicadas em cobertura.

Não houve diferença significativa entre os capins quanto à porcentagem de matéria seca e o número de folhas por perfilho, sendo verificado valores médios de $16,83 \%$ de matéria seca e 3,15 folhas por perfilho.

Para as produções de matéria verde e matéria seca, altura de plantas e acúmulo de matéria seca, os capins Mombaça e Tanzânia apresentaram médias semelhantes, porém superiores ao capim Mulato, enquanto para a eficiência de utilização do nitrogênio, o capim Mulato foi superior ao capim Mombaça, mas ambos não diferiram do capim Tanzânia (Tabela 1).

Pode-se verificar efeito linear positivo das doses de nitrogênio sobre a porcentagem de matéria seca (Figura 2a), número de folhas por perfilho (Figura 2b), altura (Figura 2c), matéria verde (Figura 2d), matéria seca (Figura 2e) e taxa de acúmulo de matéria seca (Figura 2f), enquanto a eficiência de utilização do nitrogênio aplicado (Figura 2g) ajustou-se ao modelo quadrático de regressão em função das doses de nitrogênio aplicadas em cobertura. 
Tabela 1. Produção de matéria verde (PMV) matéria seca (PMS), teor de matéria seca, número de folhas por perfilho e altura dos capins Mombaça, Mulato e Tanzânia.

\begin{tabular}{|c|c|c|c|c|c|c|c|}
\hline Capins & $\begin{array}{c}\text { Teor } \\
\text { de MS } \\
\%\end{array}$ & $\begin{array}{c}\text { Folhas/ } \\
\text { perfilho } \\
n^{\circ}\end{array}$ & Altura & ----- kg h & $a^{-1}$ & $\begin{array}{l}\text { Acúmulo } \\
\text { de MS } \\
\text { kg ha }^{-1} \text { dia }^{-1}\end{array}$ & $\begin{array}{l}\text { Eficiência } \\
\text { de uso do N } \\
\text { kg MS kg N-1 }\end{array}$ \\
\hline Tanzânia & $16,44 \mathrm{a}$ & $3,21 \mathrm{a}$ & $97,13 \mathrm{a}$ & $55333 \mathrm{a}$ & $9382,7 \mathrm{a}$ & $275,22 \mathrm{a}$ & $14,33 \mathrm{ab}$ \\
\hline Mombaça & $17,28 \mathrm{a}$ & $3,09 \mathrm{a}$ & $97,42 \mathrm{a}$ & $51866 \mathrm{a}$ & $8865,2 \mathrm{a}$ & $255,67 \mathrm{a}$ & $12,73 b$ \\
\hline Mulato & $16,77 \mathrm{a}$ & $3,16 \mathrm{a}$ & $44,71 \mathrm{~b}$ & $29033 \mathrm{~b}$ & $4593,0 \mathrm{~b}$ & $131,22 \mathrm{~b}$ & $25,21 \mathrm{a}$ \\
\hline$\overline{\mathrm{CV}(\%)}$ & 6,64 & 4,75 & 5,48 & 17,67 & 13,67 & 11,21 & 63,99 \\
\hline
\end{tabular}

Valores seguidos de mesma letra na coluna, não diferem entre si pelo teste Tukey a 5\%.

A cada $40 \mathrm{~kg} \mathrm{ha}^{-1}$ de nitrogênio aplicado ocorre redução de $0,56 \%$ na porcentagem de matéria seca das forrageiras (Figura 2a). A redução na porcentagem de matéria seca ocorre possivelmente porque a maior disponibilidade de nitrogênio estimula o crescimento das plantas, acarretando maior acúmulo de água.

Para o número de folhas por perfilho foi verificado um incremento de 0,14 folhas a cada $40 \mathrm{~kg}$ ha $^{-1}$ aplicados (Figura 2b). Resultados semelhantes foram obtidos por Garcez Neto et al. (2002), que ao estudarem alturas de corte e doses de nitrogênio sobre o capim Mombaça, observaram que o número de folhas verdes aumentou linearmente com o suprimento de nitrogênio e com as alturas de corte, com os maiores valores nas maiores doses de nitrogênio e alturas de corte. Silva et al. (2009) trabalhando com aplicação de doses crescentes de nitrogênio em duas espécies de braquiária em vasos verificaram efeito quadrático do nitrogênio no número de folhas por perfilho, sendo o maior número de folhas por perfilho encontrado com a dose de $157 \mathrm{mg} \mathrm{dm}^{-3}$. Segundo os mesmos autores o número total de folhas por perfilho é uma variável importante da planta, pois influenciadiretamente a produção de matéria seca.

Fagundes et al. (2005) avaliando aplicação de nitrogênio em Brachiaria decumbens nas quatro estações do ano, observaram efeito linear positivo do nitrogênio sobre o acumulo de matéria seca de folhas nas estações de verão, outono e inverno, e efeito quadrático na primavera. Silveira e Monteiro (2007) avaliando adubação com doses combinadas de nitrogênio e cálcio em solução nutritiva em capim Tanzânia, verificaram efeito quadrático do nitrogênio sobre o número de folhas por planta em três cortes sucessivos, o mesmo foi verificado pelos autores para o perfilhamento.

Quanto à altura, a aplicação de $40 \mathrm{~kg} \mathrm{ha}^{-1}$ de nitrogênio promoveu aumento de 4,6 cm (Figura 2c). Resultados semelhantes para a altura de plantas foram obtidos por Mota et al. (2010), que ao estudarem doses de nitrogênio e lâminas de irrigação sobre o capim pioneiro, encontraram resposta linear positiva para a combinação dos fatores. Oliveira et al. (2010) ao estudarem os efeitos da adubação nitrogenada sobre o crescimento do capim Tifton 85 (Cynodon spp. cv. Tifton 85) também encontraram efeitos significativos da adubação nitrogenada sobre a altura de plantas. Em condições de casa de vegetação, Soratto et al. (2004), estudando Panicum miliaceum observaram aumento na altura de plantas com a aplicação de adubação nitrogenada aos 25 dias após a semeadura, enquanto em estudo posterior, Soratto et al. (2007), observaram aumento na altura de plantas independentemente da época de aplicação do nitrogênio.

A cada $40 \mathrm{~kg} \mathrm{ha}^{-1}$ de nitrogênio aplicados em 
cobertura houve incremento de $4600 \mathrm{~kg} \mathrm{ha}^{-1} \mathrm{de}$ matéria verde (Figura 2d) e 809,2 $\mathrm{kg} \mathrm{ha}^{-1}$ de matéria seca (Figura 2e), ou seja, aumento de $12,32 \%$ e $13,06 \%$ respectivamente. A maior produção de matéria verde e matéria seca é em parte conseqüência do incremento no número de folhas por perfilho (Figura 2b) e na altura da forragem (Figura 2c).

Figura 2. Porcentagem de matéria seca (a), número de folhas por perfilho (b), altura (c), matéria verde (d) e matéria seca (e) das forrageiras Mombaça, Mulato e Tanzânia em função da adubação de cobertura com nitrogênio. $* *=$ significativo a $1 \%$ de probabilidade.

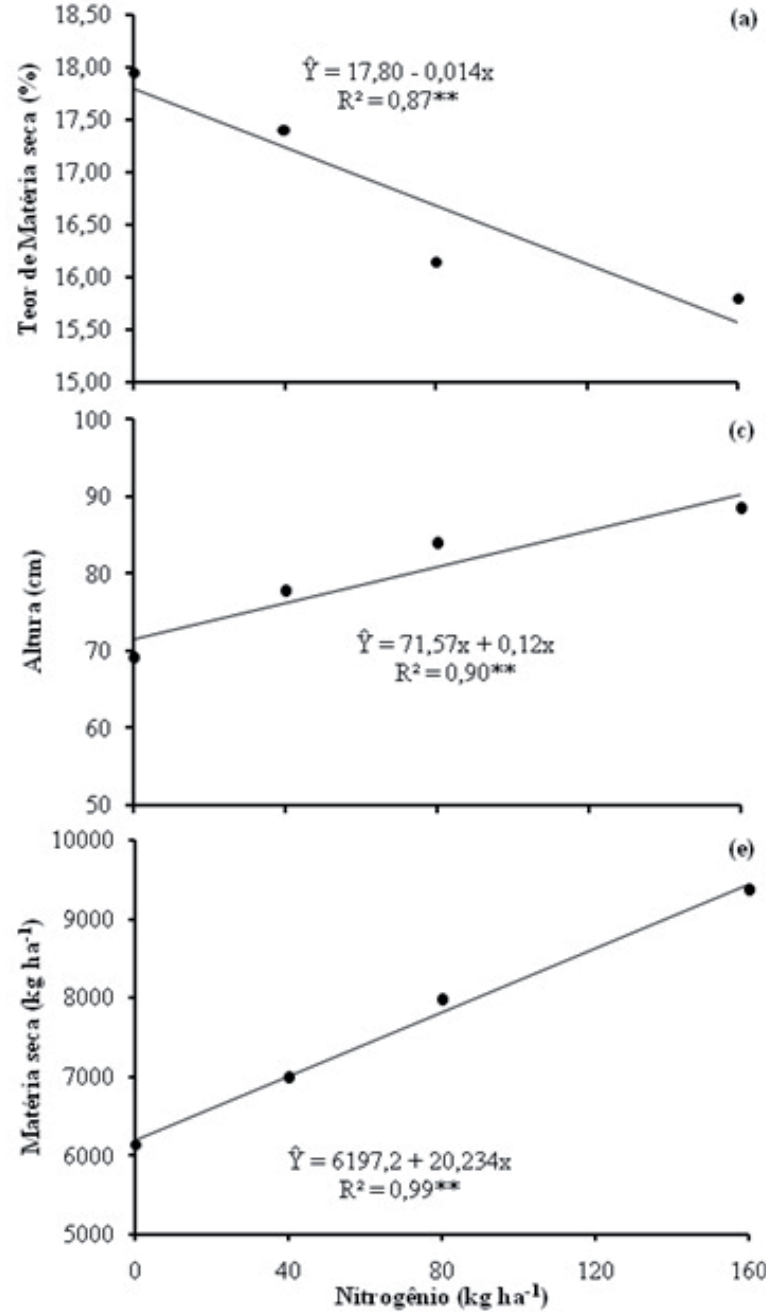

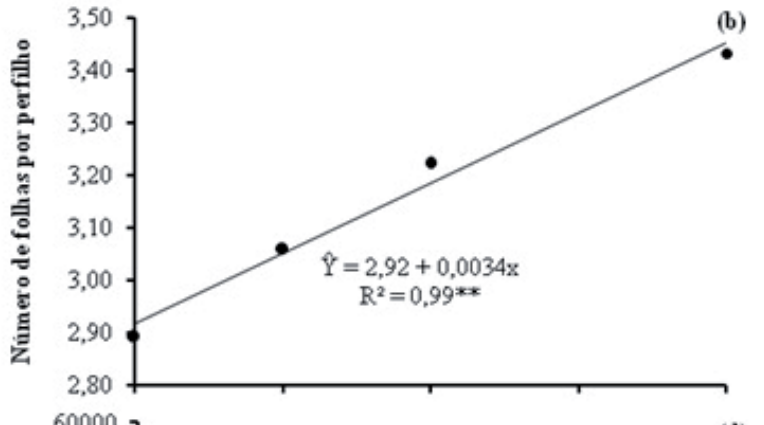
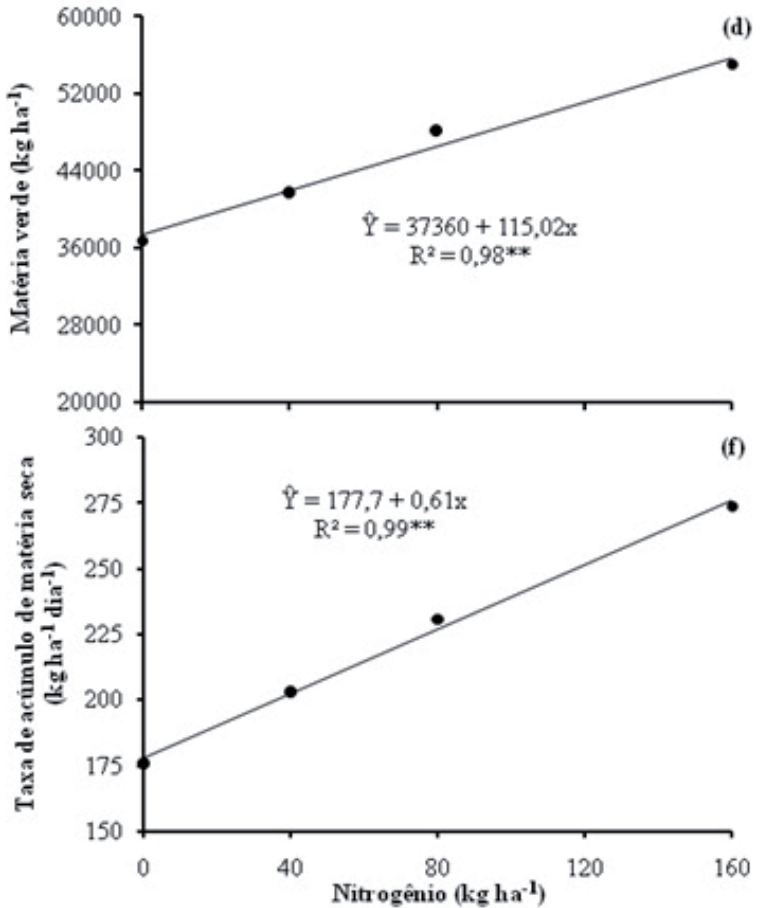

(g)

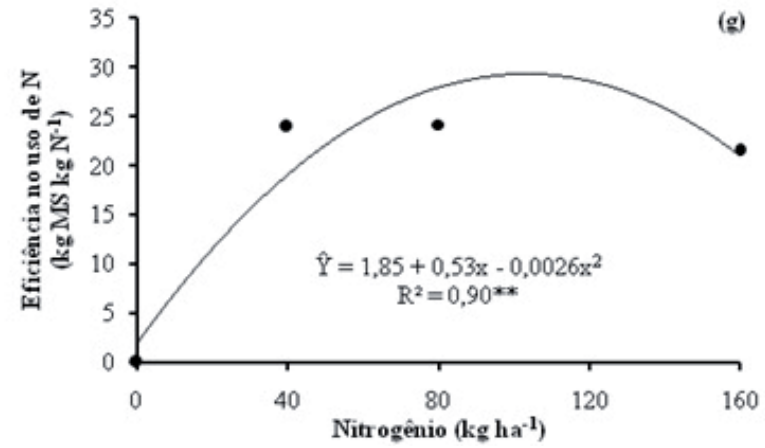


Fagundes et al. (2005) trabalhando com aplicação de nitrogênio na Brachiaria decumbens durante o ano, encontraram efeito linear das doses de nitrogênio sobre a produção de matéria seca da gramínea. Costa et al. (2009) também encontrou efeito linear do nitrogênio sobre a produção de massa seca de cultivares de Brachiaria brizantha (Marandu, Xaraés e MG-4), enquanto Santos et al. (2009) ao estudarem pastos diferidos de capim braquiária adubados com nitrogênio observaram que as massas de forragem total e dos seus componentes morfológicos aumentaram de forma linear com o aumento do período de diferimento e das doses de nitrogênio. Silveira e Monteiro (2007) avaliando adubação com doses combinadas de nitrogênio e cálcio em solução nutritiva em capim Tanzânia, verificou efeito quadrático da aplicação de nitrogênio sobre a produção de massa seca da parte aérea no primeiro corte. $\mathrm{O}$ aumento da produção de matéria seca com o aumento das doses de nitrogênio pode estar relacionado com o aumento do número de perfilhos, pois Lavres Junior e Monteiro (2003), trabalhando em vasos verificaram aumento quadrático do número de perfilhos do capim Mombaça com o aumento da dose de nitrogênio sendo que o maior número de perfilhos foi verificado com a dose de $296 \mathrm{mg} \mathrm{L}^{-1}$.

Soria et al. (2003) avaliando o efeito do nitrogênio aplicado no capim Tanzânia em diferentes laminas de água, verificaram que em todas as laminas de água a aplicação de doses crescentes de nitrogênio promoveu incremento linear da produção de massa seca total. Souza et al. (2005) avaliando os efeitos da irrigação e da adubação nitrogenada sobre a massa de forragem de cinco diferentes cultivares de Panicum maximum Jacq., concluíram que independente da irrigação, os cultivares estudados responderam à aplicação de nitrogênio quanto a produção de matéria seca.

Segundo Martuscello et al. (2009) o aumento na produção de forragem com a aplicação de nitrogênio é fato esperado em ensaios dessa natureza, devido ao conhecido efeito do $\mathrm{N}$ no acúmulo de matéria seca, pois o suprimento de $\mathrm{N}$ é um dos fatores de manejo que controla os diferentes processos de crescimento das plantas.

Para a taxa de acúmulo de matéria seca, foi observado que a cada $40 \mathrm{~kg} \mathrm{ha}^{-1}$ de $\mathrm{N}$ aplicado tinhase um acréscimo de $25 \mathrm{~kg} \mathrm{ha}^{-1} \mathrm{dia}^{-1}$ de matéria seca (Figura 2f). Resultados semelhantes foram obtidos por Moreira et al. (2009), que ao trabalharem com doses de $\mathrm{N}\left(75,150,225,300 \mathrm{~kg}\right.$ de $\left.\mathrm{N} \mathrm{ha}^{-1} \mathrm{ano}^{-1}\right)$ em dois anos consecutivos em Brachiaria decumbens cv. Basilisk, obtiveram resposta linear positiva para a taxa de acúmulo de matéria seca. Segundo os autores, pastos mantidos em mesma intensidade de pastejo e com maior disponibilidade de nitrogênio apresentam maiores taxas de acúmulo de matéria seca.

Paris et al. (2009), ao estudarem o capim Coastcros consorciado com Arachis pintoi e adubado ou não com $\mathrm{N}\left(0,100,200 \mathrm{~kg}\right.$ de $\left.\mathrm{N} \mathrm{ha}^{-1} \mathrm{ano}^{-1}\right)$ durante todas as estações não observaram diferenças na taxa de acúmulo de matéria seca em função da adubação nitrogenada. Fagundes et al. (2005) verificaram que o suprimento de nitrogênio no solo normalmente não atende à demanda das gramíneas, porém, quando há adubação nitrogenada, são observadas grandes alterações na taxa de acúmulo de matéria seca.

O estudo da eficiência de utilização do nitrogênio em sistemas produtivos é fundamental, pois á medida que a quantidade aplicada ultrapassa a capacidade da planta em absorver o nutriente para produção, o nitrogênio pode ser lixiviado ou acumular-se nos tecidos, reduzindo sua eficiência de aproveitamento (DOUGHERTY; RHYKERD, 1985). No presente estudo, a máxima eficiência de utilização do nitrogênio foi obtida com a dose de $106 \mathrm{~kg} \mathrm{ha}^{-1}$ (Figura 2g), revelando que as forrageiras estudadas não possuíram potencial para utilizar eficientemente doses superiores a esta nas condições do estudo.

A resposta à eficiência de utilização do nitrogênio pelas forrageiras é variável, Fagundes et al. (2005) trabalharam com Brachiaria decumbens 
em doses crescentes de nitrogênio observaram que com o aumento das doses houve uma redução linear na eficiência de utilização do nitrogênio. Heringer e Moojen (2002) trabalhando com milheto sob adubação nitrogenada $\left(0,150,300,450,600 \mathrm{~kg} \mathrm{ha}^{-1}\right)$ obtiveram resposta linear negativa para a eficiência de utilização do nitrogênio. Os autores observaram que houve uma progressiva redução na produção de matéria seca para cada $1 \mathrm{~kg}$ de nitrogênio, com valores de 45 e 14 para as doses de nitrogênio de 150 e $600 \mathrm{~kg} \mathrm{ha}^{-1}$, respectivamente.

A análise de correlação linear de Pearson entre as características estudadas dos capins revelou correlação positiva da produção de matéria verde com a taxa de acúmulo e produção de matéria seca $(p<0,05)$ em todos os capins, enquanto para Mombaça e Tanzânia, essa variável correlacionouse com a altura das plantas $(p<0,05)$, e somente para o capim Mulato houve correlação com a eficiência de uso do nitrogênio $(\mathrm{p}<0,05)$.

A produção de matéria seca apresentou correlação positiva com todas as demais variáveis em todos os capins (Tabela 2), enquanto a altura de plantas correlacionou-se de forma positiva com o número de folhas e com a taxa de acúmulo de matéria seca $(p<0,05)$ em todos os capins, porém, apresentou correlação significativa com a eficiência de uso do nitrogênio apenas para o capim Mombaça. O número de folhas apresentou correlação positiva com a taxa de acúmulo e com a eficiência de uso do nitrogênio em todos os capins exceto para o Mulato, no qual correlacionou-se somente com a taxa de acúmulo. A eficiência de uso do nitrogênio e a taxa de acúmulo de matéria seca apresentaram correlação positiva em todos os capins estudados $(\mathrm{p}<0,01)$.

Tabela 2. Estimativas dos coeficientes de correlação linear de Pearson simples entre as características estudadas.

\begin{tabular}{|c|c|c|c|c|c|}
\hline & $\begin{array}{c}\text { Produção } \\
\text { de MS }\end{array}$ & $\begin{array}{c}\text { Altura } \\
\text { de Plantas }\end{array}$ & $\begin{array}{l}\text { Número } \\
\text { de Folhas }\end{array}$ & $\begin{array}{c}\text { Taxa de } \\
\text { acúmulo de MS }\end{array}$ & $\begin{array}{c}\text { Eficiência } \\
\text { de Uso do N }\end{array}$ \\
\hline \multicolumn{6}{|l|}{ Tanzânia } \\
\hline Produção de MV & $0,71 * *$ & $0,14^{\mathrm{ns}}$ & $0,73 * *$ & $0,71 * *$ & $0,40^{\mathrm{ns}}$ \\
\hline Produção de MS & & $0,57 *$ & $0,67 * *$ & $1,00 * *$ & $0,74 * *$ \\
\hline Altura de Plantas & & & $0,62 * *$ & $0,57^{*}$ & $0,46^{\mathrm{ns}}$ \\
\hline Número de Folhas & & & & $0,67 * *$ & $0,35^{*}$ \\
\hline Taxa de Acúmulo de MS & & & & & $0,75^{* *}$ \\
\hline \multicolumn{6}{|l|}{ Mombaça } \\
\hline Produção de MV & $0,90 * *$ & $0,86 * *$ & $0,88 * *$ & $0,91 * *$ & $0,48^{\mathrm{ns}}$ \\
\hline Produção de MS & & $0,84 * *$ & $0,84 * *$ & $1,00 * *$ & $0,74 * *$ \\
\hline Altura de Plantas & & & $0,80 * *$ & $0,84 * *$ & $0,61 *$ \\
\hline Número de Folhas & & & & $0,84 * *$ & $0,57 *$ \\
\hline Taxa de Acúmulo de MS & & & & & $0,74 * *$ \\
\hline \multicolumn{6}{|l|}{ Mulato } \\
\hline Produção de MV & $0,61 *$ & $0,49 *$ & $0,38^{\mathrm{ns}}$ & $0,61 *$ & $0,58 *$ \\
\hline Produção de MS & & $0,79 * *$ & $0,86^{* *}$ & $1,00^{* *}$ & $0,70 * *$ \\
\hline Altura de Plantas & & & $0,68 * *$ & $0,79 * *$ & $0,51^{\mathrm{ns}}$ \\
\hline Número de Folhas & & & & $0,86^{* *}$ & $0,48^{\mathrm{ns}}$ \\
\hline Taxa de Acúmulo de MS & & & & & $0,70 * *$ \\
\hline
\end{tabular}

ns: Não significativo; ${ }^{*}{ }^{* *}$ : Significativo a 5 e a $1 \%$ respectivamente pelo teste $\mathrm{t}$; 
Os resultados encontrados eram esperados, pois o aumento da produção de forragem com o aumento a altura do dossel ocorre devido ao aumento da produção de colmos, que ao se alongarem, não somente incrementam produção de forragem, como também proporcionam à planta a sustentação de um maior número de folhas, ocasionando conseqüentemente maior número de folhas por perfilhos.

Segundo Griffiths, Hodgson e Arnold (2003), o estudo da altura do dossel forrageiro possui papel fundamental no manejo de forrageiras sob pastejo dos animais, por ser um fator parcial de regulação da profundidade do bocado. Niklas (1994), cita a relação entre o alongamento do colmo, a altura do dossel e o número de folhas. Segundo ao autor, aumentos em altura do dossel quase sempre conduzem a um aumento na proporção de colmos devido ao aumento no seu diâmetro, que altera-se em proporção direta à força requerida para suportar as folhas inseridas no perfilho. Em relação ao número de folhas por perfilho, segundo Rodrigues et al. (2008), apesar de o nitrogênio aumentar a quantidade de folhas, esse nutriente aumenta também a quantidade de colmos na forragem, reduzindo a relação entre ambos, porém, esse efeito negativo pode ser compensado parcialmente ou totalmente pelo benefício do aumento em produção de fitomassa.

A associação do da altura de plantas, número de folhas e produção de matéria seca interferiram diretamente na taxa de acúmulo de matéria seca. A taxa de acúmulo de forragem varia amplamente em função de condições edafo-climáticas e de manejo, de forma que Gomide e Gomide (1997), simularam diferentes alturas de pastejo em Brachiaria decumbens e verificaram que a taxa de acúmulo de forragem apresentou resposta quadrática em função da variação em altura do dossel, enquanto Santos; Corsi e Balsalobre (1999), ao estudaram o efeito de períodos de descanso (28, 38 e 48 dias) sobre a taxa de acúmulo de matéria seca dos capins Tanzânia e Mombaça e constataram uma maior massa de forragem para o maior período de descanso.

\section{Conclusões}

Os capins Mombaça e Tanzânia possuem potencial semelhante para produção de matéria verde e seca, superando o capim Mulato.

A aplicação de nitrogênio aumenta a produção de matéria verde e seca, a taxa de acúmulo de matéria seca, a altura do dossel e o número de perfilhos dos capins Mombaça, Tanzânia e Mulato.

A eficiência máxima do uso do $\mathrm{N}$ para a produção de matéria seca dos capins Mombaça, Tanzânia e Mulato foi obtida com a dose de $108 \mathrm{~kg} \mathrm{ha}^{-1}$.

\section{Referências}

COSTA, K. A. P.; FAQUIN, V.; OLIVEIRA, I. P. Doses e fontes de nitrogênio na recuperação de pastagens do capim-marandu. Arquivo Brasileiro de Medicina Veterinária e Zootecnia, Belo Horizonte, v. 62, n. 1, p. 192-199, 2010.

COSTA, K. A. P.; OLIVEIRA, I. P.; FAQUIN, V.; SILVA, G. P.; SEVERIANO, E. C. Produção de massa seca e nutrição nitrogenada de cultivares de Brachiaria brizantha (A. Rich) Stapf sob doses de nitrogênio. Ciência e Agrotecnologia, Lavras, v. 33, n. 6, p. 1578$1585,2009$.

CRITCHFIELD, H. J. General climatology. Englewood Cliffs: Prentice-Hall, 1960. 465 p.

DOUGHERTY, C. T.; RHYKERD, C. L. The role of nitrogen in forage-animal production. In: HEATH, M. E.; BARNES, R. F. METCALFE, D. S. (Ed). Forages: the science of grassland agriculture. 5. ed. Iowa: State University, 1985. p. 318-325.

EMPRESA BRASILEIRA DE PESQUISA AGROPECUÁRIA - EMBRAPA. Centro Nacional de Pesquisa de Solos. Sistema brasileiro de classificação de solos. Brasília: EMBAPA, 2006. 412 p.

FAGUNDES, J. L.; FONSECA, D. M.; GOMIDE, J. A.; NASCIMENTO JUNIOR, D.; VITOR, C. M. T.; MORAIS, R. V.; MISTURA, C; REIS, G. C.; MARTUSCELLO, J. A. Acúmulo de forragem em pastos de Brachiaria decumbens adubados com nitrogênio. Pesquisa Agropecuária Brasileira, Brasília, v. 40, n. 4, p. 397-403, 2005. 
FERREIRA, D. F. SISVAR: um programa para análises estatísticas e ensino de estatística. Revista Symposium, Lavras, v. 6, n. 2, p. 36-41, 2008.

FRANÇA, A. F. S.; BORJAS, A. L. R.; OLIVEIRA, E. R.; SOARES, T. V.; MIYAGI, E. S.; SOUSA, V. R. Parâmetros nutricionais do capim-tanzânia sob doses crescentes de nitrogênio em diferentes idades de corte. Ciência Animal Brasileira, Goiânia, v. 8, n. 4, p. 695703, 2007.

GARCEZ NETO, A. F.; NASCIMENTO JUNIOR, D.; REGAZZI, A. J.; FONSECA, D. M.; MOSQUIM, P. R.; GOBBI, K. F. Respostas morfogênicas e estruturais de Panicum maximum cv. mombaça sob diferentes níveis de adubação nitrogenada e alturas de corte. Revista Brasileira de Zootecnia, Viçosa, v. 31, n. 5, p. 18901900, 2002.

GOMIDE, C. A.; GOMIDE, J. A. Morfogênese e análise de crescimento de cultivares de Panicum maximum. In: REUNIÃO ANUAL DA SOCIEDADE BRASILEIRA DE ZOOTECNIA, 34., 1997, Juiz de Fora. Anais... Juiz de Fora: SBZ, 1997. p. 403-406.

GRIFFITHS, W. M.; HODGSON, J.; ARNOLD, G. C. The influence of sward canopy structure on foraging decisions by grazing cattle. II. Regulation of bite depth. Grass and Forage Science, Zurique, v. 58, n. 2, p. 25137, 2003.

HERINGER, I.; MOOJEN, E. L. Potencial produtivo, alterações da estrutura e qualidade da pastagem de milheto submetida a diferentes níveis de nitrogênio, Revista Brasileira de Zootecnia, Viçosa, v. 31, n. 2, p. 875-882, 2002. Suplemento.

LAVRES JUNIOR, J.; MONTEIRO, F. A. Perfilhamento, área foliar e sistema radicular do capim-Mombaça submetido a combinações de doses de nitrogênio e potássio. Revista Brasileira de Zootecnia, Viçosa, v. 32, n. 5, p. 1068-1075, 2003.

MARTUSCELLO, J. A.; FARIA, D. J. G.; CUNHA, D. N. F. V.; FONSECA, D. M. Adubação nitrogenada e partição de massa em plantas de Brachiaria brizantha cv. xaraés e Panicum maximum x Panicum infestum cv. massai. Ciência e Agrotecnologia, Lavras, v. 33, n. 3, p. 663-667, 2009.

MOREIRA, F. L. M.; MOTA, F. O. B.; CLEMENTE, C. A.; AZEVEDO, B. M.; BOMFIM, G. V. Adsorção de fósforo em solos do Estado do Ceará. Revista Ciência Agronômica, Fortaleza, v. 37, n. 1, p. 7-12, 2006.

MOREIRA, L. M.; MARTUSCELLO, J. A.; FONSECA, D. M.; MISTURA, C.; MORAIS, R. V.; RIBEIRO JÚNIOR, J. I. Perfilhamento, acúmulo de forragem e composição bromatológica do capim-braquiária adubado com nitrogênio. Revista Brasileira de Zootecnia, Viçosa, v. 38, n. 9, p. 1675-1684, 2009.

MOTA, V. J. G.; REIS, S. T.; SALES, E. C. J.; ROCHA JÚNIOR, V. R.; OLIVEIRA, F. G.; WALKER, S. F.; MARTINS, C. E.; CÓSER, A. C. Lâminas de irrigação e doses de nitrogênio em pastagem de capim-elefante no período seco do ano no norte de Minas Gerais. Revista Brasileira de Zootecnia, Viçosa, v. 39, n. 6, p. 11911199, 2010.

NIKLAS, K. J. Plant allometry: the scaling process. Chicago: University of Chicago Press; Chicago: Illinois, USA, 1994.

OLIVEIRA, A. P. P.; ROSSIELLO, R. O. P.; GALZERANO, L.; COSTA JÚNIOR, J. B. G.; SILVA, R. P.; MORENZ, M. J. F. Respostas do capim-Tifton 85 à aplicação de nitrogênio: cobertura do solo, índice de área foliar e interceptação da radiação solar. Arquivos Brasileiros de Medicina Veterinária e Zootecnia, Belo Horizonte, v. 62, n. 2, p. 429-438, 2010.

PARIS, W.; CECATO, U.; BRANCO, A. F.; BARBERO, L. M.; GALBEIRO, S. Produção de novilhas de corte em pastagem de Coastcross-1 consorciada com Arachis pintoi com e sem adubação nitrogenada. Revista Brasileira de Zootecnia, Viçosa, v. 38, n. 1, p. 122-129, 2009.

PREMAZZI, L. M.; MONTEIRO, F. A.; CORRENTE, J. E. Perfilhamento em Capim bermuda cv. Tifton $85 \mathrm{em}$ resposta a doses e ao momento de aplicação do nitrogênio após o corte. Scientia Agrícola, Piracicaba, v. 60, n. 3, p. 565- 571, 2003.

RODRIGUES, R. C.; MOURÃO, G. B.; BRENNECKE, K.; LUZ, P. H. de C.; HERLING, V. R. Produção de massa seca, relação folha/colmo e alguns índices de crescimento do Brachiaria brizantha cv. Xaraés cultivado com a combinação de doses de nitrogênio e potássio. Revista Brasileira de Zootecnia, Viçosa, v. 37, n. 3, p. 394-400, 2008.

SANTANA, G. S.; BIANCHI, P. P. M.; MORITA, I. M.; ISEPON, J .O.; FERNANDES, F. M. Produção e composição bromatológica da forragem do capimmombaça (Panicum maximum Jacq.), submetidos a diferentes fontes e doses de corretivo de acidez. Semina: Ciências Agrárias, Londrina, v .31, n. 1, p. 241-246, 2010.

SANTOS, I. P. A.; PINTO, J. C.; SIQUEIRA, J. O.; MORAIS, A. R.; SANTOS, C. L. Influência do fósforo, micorriza e nitrogênio no conteúdo de minerais de Brachiaria brizantha e Arachis pintoi consorciados. Revista Brasileira de Zootecnia, Viçosa, v. 31, n. 2, p. 605-616, 2002.

SANTOS, M. E. R.; FONSECA, D. M.; BALBINO, 
E. M.; MONNERAT, J. P. I. S.; SILVA, S. P. Capimbraquiária diferido e adubado com nitrogênio: produção e características da forragem. Revista Brasileira de Zootecnia, Viçosa, v. 38, n. 4, p. 650-656, 2009.

SANTOS, P. M.; CORSI, M.; BALSALOBRE, M. A. A. Efeito da freqüência de pastejo e da época do ano sobre a produção e a qualidade em Panicum maximum cvs, Tanzânia e Mombaça, Revista Brasileira de Zootecnia, Viçosa, v. 28, n. 2, p. 244-249, 1999.

SILVA, C. C. F.; BONOMO, P.; PIRES, A. J. V.; MARANHÃO, C. M. A.; PÂTES, N. M. S.; SANTOS, L. C. Características morfogênicas e estruturais de duas espécies de braquiária adubadas com diferentes doses de nitrogênio. Revista Brasileira de Zootecnia, Viçosa, v. 38, n. 4, p. 657-661, 2009.

SILVA, D. J.; QUEIROZ, A. C. Análise de alimentos: métodos químicos e biológicos. Viçosa: UFV, 2006. 235 p.

SILVEIRA, C. P.; MONTEIRO, F. A. Morfogênese e produção de biomassa do capim-tanzânia adubado com nitrogênio e cálcio. Revista Brasileira de Zootecnia, Viçosa, v. 36, n. 2, p. 335-342, 2007.

SORATTO, R. P.; LIMA, E. V.; SILVA, T. R. B.; BOARO, C. S. F.; CATANEO, A. C. Nitrogen fertilization of fall panicum cultivars (Panicum dichotomiflorum Michx.): biochemical and agronomical aspects. Scientia Agrícola, Piracicaba, v. 61, n. 1, p. 82-87, 2004.

SORATTO, R. P.; CARDOSO, S. M.; SILVA, A. H.; COSTA, T. A. M.; PEREIRA, M.; CARVALHO, L. A. Doses e épocas de aplicação de nitrogênio em cobertura na cultura do painço (Panicum miliaceum L.). Ciência e Agrotecnologia, Lavras, v. 31, n. 6, p. 1661-1667, 2007.

SORIA, L. G. T.; COELHO, R. D.; HERLING, V. R.; PINHEIRO, V. Resposta do capim Tanzânia a aplicação do nitrogênio e de lâminas de irrigação. I: produção de forragem. Revista Brasileira de Engenharia Agrícola e Ambiental, Campina Grande, v. 7, n. 3, p. 430-436, 2003.

SOUZA, E. M.; ISEPON, O. J.; ALVES, J. B.; BASTOS, J. F. P.; LIMA, R. C. Efeitos da irrigação e adubação nitrogenada sobre a massa de forragem de cultivares de Panicum maximum Jacq. Revista Brasileira de Zootecnia, Viçosa, v. 34, n. 4, p. 1146-1155, 2005.

VITOR, C. M. T.; FONSECA, D. M.; CÓSER, A. C.; MARTINS, C. E.; NASCIMENTO JÚNIOR, D.; RIBEIRO JÚNIOR, J. I. Produção de matéria seca e valor nutritivo de pastagem de capim-elefante sob irrigação e adubação nitrogenada. Revista Brasileira de Zootecnia, Viçosa, v. 38, n. 3, p. 435-442, 2009. 
